\title{
Carbon Dust na comunicação científica - potencialidades e perspetiva
}

\author{
Sofia M. Ferreira \& Fernando J. Correia \\ ... \\ E-mail: sofiamdsfegmail.com
}

\begin{abstract}
Resumo
A utilização da ilustração científica, para comunicar e divulgar ciência, tem como base a compilação/seleção e a codificação visual de uma mensagem, no formato de imagem construída de modo a poder transmitir o conhecimento científico, de forma fluída e eficaz, informando. Ela deve também estimular e motivar uma necessidade do observador. Comunicar Ciência de forma visual denota uma forte dependência das técnicas de expressão plástica adotadas para atingir um determinado fim figurativo/representativo de forma expedita, credível e mimético com o objeto de estudo, ideia ou modelo real a ilustrar. A ilustração científica também é sublimada pelas potencialidades do carvão e a evolução técnica para a "pintura"

proporcionada pelo pó de carvão - Carbon Dust. O seu potencial foi realçado através da ilustração médica e dos trabalhos pioneiros e intemporais de Max Brödel (1911). A contemporaneidade da técnica é tal que, ainda hoje, é aí leccionada a metodologia proposta por Brödel, tendo inclusive ultrapassado fronteiras (como no Canadá e na Europa, mais precisamente no Curso de Formação em Ilustração Científica ministrado na Universidade de Aveiro). Nesta comunicação pretendeu-se realçar a importância da técnica do Carbon Dust aplicada à ilustração científica, num sentido mais amplo, realçando as suas potencialidades na figuração anatómica.
\end{abstract}

Palavras-chaves: ilustração científica; comunicar e divulgar ciência; ilustração médica; técnica do Carbon Dust.

\begin{abstract}
The use of scientific illustration to communicate and disseminate science is based on the collection / selection and visual encoding of a message, in the format of an image constructed to be able

to transmit scientific knowledge in a fluid and effective way. It should also stimulate and motivate an observer's need. To communicate Science visually denotes a strong dependence on plastic expression
\end{abstract}


techniques used to achieve a particular purpose figurative / representative in an expeditious manner, credible and mimetic with the study object, idea or real model to illustrate. The scientific illustration is also sublimated by coal potentialities and the technical evolution of the "painting" provided by coal dust - Carbon Dust. Its potential was emphasized by medical illustration and by Max Brodel (1911) pioneers and timeless works. The contemporaneity technique is such that, even today, it is taught the proposed Brodel's methodology, having even exceeded borders (as in Canada and Europe, more precisely in the Training Course in Scientific Illustration taught at the University of Aveiro). In this communication it is intended to enhance the importance of Carbon Dust technique applied to scientific illustration, in a broader sense, enhancing their potential in the anatomical figuration.

Keywords: scientific illustration; communicate and disseminate science; medical illustration; Carbon Dust technique.

C ONSIDERA-SE um desenho/ilustração científica, toda e qualquer imagem desenhada que exibe rigor, correção e objectividade na mensagem que transmite, sempre no domínio do conhecimento científico e dentro do estado da Ciência patente e aceite nesse momento. A ilustração científica tem assim a função prioritária de codificar visualmente e veicular uma mensagem científica (uma ideia ou tese, uma interpretação, uma observação), de forma tacitamente credível, acessível e passível de ser entendida e utilizada por várias audiências (especializadas e/ou não-especializadas), tanto em Portugal como em qualquer outra parte do Mundo, ultrapassando obstáculos idiomáticos, culturais e outros (Correia, 2009a).

Uma ilustração científica é uma imagem pensada e construída que representa com rigor diversos assuntos ligados às Ciências, adaptando-se a domínios tão diferentes como a Biologia, a Medicina, a Paleontologia, a Geologia, a Antropologia, etc. Para tal e tendo como objetivo maior a apreensão desse conhecimento em particular, deve sempre respeitar três premissas basilares e simultâneas na sua construção e formatação: 1) compilar/condensar/informar; 2) transmitir o conhecimento científico, de forma fluída e eficaz, informando e 3) estimular/motivar através de uma codificação visual da informação (Correira, 2009a, 2010, 2011a e 2011b). Só assim ela poderá ter valor documental e ser utilizada para comunicar e divulgar ciência, estimulando e motivando uma necessidade do observador. Comunicar Ciência de forma visual denota 
uma forte dependência das técnicas de expressão plástica adotadas para atingir um determinado fim figurativo/representativo de forma expedita, credível e mimético com o objeto de estudo, ideia ou modelo (arquétipo) real a ilustrar. Segundo Correia (2011c:45), "converter Ciência em Imagem desenhada é, antes de tudo, um exercício de reflexão e interpretação, uma incessante procura de contornos heurísticos, da Universalidade e do Imediatismo, da Comunicabilidade. Só depois é traço e cor". Por todas as premissas e convenções a que é sujeita, dentro do discurso científico a que está subordinada, considera-se que a ilustração científica é assim uma imagem útil, credível e honesta.

Desde os tempos mais remotos da Humanidade, o Homem tem recorrido a desenhos/esboços para comunicar, como o testemunham numerosas pinturas rupestres (os primeiros murais), no sentido de extravasar e ir além do indivíduo (permitir que outro absorva, interiorize e faça uso de um conhecimento que não é da sua génese). Um exemplo, com mais de 18000 anos, são as pinturas rupestres da gruta Chauvet (localizada na Ardèche, França) atribuídas à época do Paleolítico médio superior e descoberta por acaso, em 1994, pelo espeleólogo Jean-Marie Chauvet. Esta estação pré-histórica reúne mais de mil pinturas e gravuras e onde se representaram cerca de 425 animais de 14 espécies diferentes (Combier \& Jouves, 2014), de grande qualidade estética e rigor - se tivermos em conta as restrições técnicas à época e limitações na metodologia do desenho em si, enquanto função de representação.

A comunicação visual através do desenho faz assim parte da natureza e da essência do Homem desde os primórdios da sua Cultura - é algo que ilustra e elucida, que torna mais claro, que ilumina. Neste sentido, e ao longo dos séculos, vários dos materiais utilizados nesses primeiros murais, foram sendo aperfeiçoados entre os quais se destacam as tintas criadas a partir da mistura de um pigmento com uma gordura (derivando daí os óleos, ou até o conceito das minas dos lápis de cor) ou ainda o carvão natural (arcaico, mas que sobreviveu na sua simplicidade até à atualidade na sua forma natural, quando muito sintetizado). O carvão vegetal ou carvão natural pode ser obtido através da queima controlada de vários tipos de madeira de árvores típicas das regiões temperadas, como o salgueiro, a tília, a nogueira, ou ainda arbustos, como a videira. A condição essencial para a adequação é a homogeneidade do material lenhoso ao longo do ramo, capaz de exibir uma boa densidade após a queima, traduzível numa multiplicidade de negros por ação de risco. Pela condição do próprio fabrico (redução da matéria orgânica à sua forma carbo- 
nizada), o carvão é um material friável e de difícil conservação. Atualmente pode ser disponibilizado em várias formas, com diferentes características: 1) carvão em galho natural quando se apresenta na sua forma original de ramo carbonizado, sendo o mais suave o galho de vinha; 2) carvão em barra regular de cerca de $18 \mathrm{~cm}$ de comprimento e um máximo de cerca de $1 \mathrm{~cm}$ de diâmetro, de aspeto cilíndrico ou paralelepipédico e em três consistências: macia, média e dura; 3) carvão sintético, mais resistente, obtido pela redução a pó de madeira carbonizada, posteriormente consolidada com um ligante e que depois é injetada e comprimida em formas que permitam o risco ( 9 a $12 \mathrm{~cm}$ de comprimento e uma grossura de cerca de $0,6 \mathrm{~cm})$; 4) lápis de carvão, com uma gama de expressão de traço que vai do 6B (muito macio) ao HB (duro), e em que basicamente o carvão sintético é utilizado na produção de minas cilíndricas de pequena espessura e cuja resistência à quebra é assegurada pelo envolvimento em capa de papel enrolado (em tortillon) ou madeira de cedro americano e 5) carvão em pó (Stanyer, 2003).

Por ser um material com uma muito fraca aderência ao papel (sem capacidade adesiva ou complementos cerosos), facilmente se subtrai à superfície onde foi depositado, razão pela qual desde a Idade Média a ele se recorre mais no intuito de realizar esboços preliminares que sirvam de base a posterior aplicação de tintas com capacidade opacificadora (óleo ou têmpera). A partir do Renascimento, tendo em conta que os materiais para a elaboração dos efeitos de luz/sombra começam a ser privilegiados no desenho, adquire uma expressão mais tonal e uma mais distintiva receção. De facto e por volta do século XVI este torna-se o instrumento mestre para a realização de figuras movimentadas, adquirindo a "arte do carvão"o estatuto de disciplina própria e independente no mundo das Belas Artes, com ampla difusão e aceitação entre os artistas dos ateliers venezianos, florentinos e romanos.

No campo da ciência, sendo que o que importa é a massificação do tratado científico (divulgação e disseminação) e não a singularidade da obra (que no campo artístico se quer não somente original, como única), o certo é que o carvão não será adoptado como técnica para a execução das primeiras imagens a serem reproduzidas nas obras científicas por então editadas. Esta realidade mantem-se inalterada, não por causas próprias das limitações da técnica em si, mas sim das técnicas de reprodução através da impressão da imagem desenhada - algo que só mudou com o advento do offset, em 1904. Volvido um século e com o advento da técnicas de impressão digital a partir de 1993, 
a ilustração científica executada em carvão ganha assim uma outra oportunidade, dinamismo e potencialidades (Correia \& Ismar, in publication).

A ilustração científica, no seu sentido mais contemporâneo e de como hoje a entendemos, apropriou-se também de mais esta técnica de expressão plástica como uma outra ferramenta para atingir os seus objetivos na complementaridade do discurso científico, mais ainda após a sua evolução de mono-risco para um poli-risco que simula o efeito de continuidade propiciado pela "pintura" a pincel seco com pó de carvão - e que originalmente se designou por Carbon Dust. O seu potencial foi realçado através da ilustração médica e dos trabalhos pioneiros e intemporais do jovem artista alemão Paul Heinrich Max Brödel (1870-1941), que viria a ser o primeiro Diretor do Departamento de Artes aplicadas à Medicina, da Universidade John Hopkins (1911), em Baltimore. Este dotado artífice chega a essa universidade, sem formação em ciência e a convite de Franklin P. Mall (1862-1917; futuro Diretor do Serviço de Anatomia), em 1894, integrando os serviços da recém-fundada Faculdade de Medicina. No entanto, as suas elevadas competências na tradução gráfica de observações médicas, permite-lhe ser tutorado pelo professor de ginecologia clínica Howard Atwood Kelly (1858-1943), que o formata para as dificuldades do que se lhe iria exigir: até 1898, produz 154 ilustrações de elevada qualidade para o primeiro volume do livro de Kelly "Operative Gynecology", seguindose cinco anos mais tarde, o segundo volume com 207 ilustrações de Brödel. De todo o processo, segundo Schultheiss, Engel, Crosby, Lees, Truss \& Jonas (2000 apud:1137) Max Brödel intuitivamente assumiu uma importante conclusão que seria determinante para o seu trabalho posterior: "É necessário para originar um tipo diferente de imagem, criar uma que mostre muito mais do que qualquer fotografia jamais poderia fazer. $\mathrm{O}$ artista deve compreender plenamente o assunto de cada ponto de vista: anatómico, topográfico, histológico, patológica, médico e cirúrgico. Destes conhecimentos acumulados cresce uma imagem mental, a partir do qual ele delimita o plano do futuro desenho. O planeamento da imagem, portanto, é a coisa mais importante, não a sua execução."Se por um lado Brödel teve uma formação clássica no campo das artes plásticas, por outro lado e mercê da continuada prática médica (observação) ganhou a clareza suficiente para perceber a extrema importância em se inteirar com rigor e objetividade das noções científicas necessárias aos temas a ilustrar. Assim e ao longo da sua carreira de ilustrador médico, foi incentivado e motivado a realizar aturados estudos de anatomia e patologia em 
cadáveres, bem como a frequentar as salas de operações, ou seja, ele mesmo se tornou um anatomista. Grande conhecedor dos tecidos vivos, assumiu o papel de um verdadeiro cientista em uroginecologia, realizando importantes contribuições para a medicina, tais como "Brödel white line" ou ainda "the Brödel suture". Mas não só se distinguiu no campo científico, como também em termos mais artístico, ao ser o responsável pelo desenvolvimento de uma nova técnica de desenho recorrendo a um material simples, mas expedito, que hoje dá pelo nome de Carbon Dust ou pó de carvão (Froeshner \& Druckenbrod, 2003; Schultheiss et al., 2000; Schultheiss \& Jonas, 1999).

A contemporaneidade da técnica é tal, que ainda hoje, esse método de figuração suportada pela pintura em seco com carvão é aí leccionada, a par do que sucede em vários outros países. Por exemplo, em 1925, foi instituído no Canadá o Departamento de Serviço de Arte Médica da Universidade de Toronto, por Maria Wishart. Com o início da Segunda Guerra Mundial, o Dr. J. C. B. Grant vê a oportunidade, através de uma equipa de ilustradores essencialmente femininos e altamente qualificados, de criar um Atlas que visualmente descrevesse os processos anatómicos humanos. Esta publicação, Grant - Atlas de Anatomia, teve um enorme impacto na altura e ainda hoje constitui uma obra de referência na formação dos estudantes de medicina em todo o mundo (Czegledy, 2010).

Na Europa, mais precisamente em Portugal, um país com tradições seculares no âmbito da figuração naturalista (biológica), podemos avançar que muitos dos primeiros ilustradores científicos portugueses (por então designados por riscadores) e que acompanharam as expedições científicas do período dos Descobrimentos, também terão recorrido ao carvão. Por outro lado e no contexto de formação, e já no século XVIII, inicia-se o ensino formal dos princípios que regem a ilustração científica na Casa do Risco. Já em meados do século XX, surgem várias disciplinas no âmbito do ensino universitário ligadas à ilustração, as quais devido a reforma do Ensino Superior que se seguiu à Revolução dos Cravos (1974) deixaram de existir. Será necessário esperar o ano de 1996, com a instituição da disciplina Métodos de Ilustração Biológica, na Universidade de Évora e ministrada pelo Dr. Fernando Correia, para um "renascimento"da ilustração científica propriamente dita enquanto disciplina integrada em cursos superiores de ciências naturais e num contexto do ensino formal (Correia, 2010). Mais tarde, em 2011, o Departamento de Biologia da Universidade de Aveiro aposta na edificação do Laboratório de Ilustração Ci- 
entífica (LIC) e ainda no Curso de Formação em Ilustração Científica (CFIC) ambos criados e sob a direção do Dr. Fernando Correia, o qual retoma a tradição do ensino atualizado das técnicas de carvão, por se reconhecer a sua pertinência e atualidade.

No intuito de demonstrar as potencialidades da aplicação desta técnica também à figuração biológica, além da médica, e a sua importância no contexto da ilustração científica enquanto vertente visual da comunicação científica, representou-se a espécie de crustáceo cuja frequência de ocorrência em Aveiro é elevada - o caranguejo-verde (Carcinus maenas; Filo Arthropoda, Família Portunidae). Sendo que a ilustração científica de uma espécie não é o desenhar de um indivíduo, mas assenta na criação de um modelo ou arquétipo visual que seja representativo do cumulativo das características que a identificam, seguiu-se a metodologia acima descrita em 3 passos.

Antes de se iniciar o trabalho gráfico e a escolha da pose em função do objetivo a alcançar, foi imprescindível uma extensa pesquisa de informação descritiva e visual por forma a listar todos os carateres com valor diagnosticante, passíveis de serem figurados e que promovam a identificação da espécie de forma inequívoca. Carcinus maenas é uma espécie invasora que apresenta dimorfismo sexual (o indivíduo masculino apresenta um abdômen de forma triangular, enquanto as fêmeas um abdômen de forma mais arredondado). Pertencendo a ordem Decapoda exibe uma carapaça grossa que apresenta cabeça e tórax soldados entre si (formando o cefalotórax), de abdómen reduzido e olhos pedunculados e móveis. Esta espécie distingue-se das outras por apresentar: 1) três dentes arredondados na fronte; 2) bordos ântero-laterais da carapaça providos de cinco dentes dirigidos para diante; 3) último artículo do quinto par de patas caracteriza-se por ser estreito e agudo; 4) aproximadamente $7 \mathrm{~cm}$ de largura e 5) de coloração esverdeada (Saldanha, 2003; Barres \& Muñoz, 2000).

Face a abundância da espécie na costa de Aveiro, foi possível estudar e observar vários indivíduos da espécie, que foram igualmente fotografados, um dos quais foi ainda preparado e montado na posição escolhida (em placa de esferovite e recorrendo a alfinetes para o posicionamento correto do corpo e apêndices), sendo posteriormente conservado (por congelação), para futuras observações na eventualidade de ser necessário esclarecer dúvidas pontuais sobre a anatomia da espécie (figura 1). A escolha da pose em vista dorsal tem como justificação o ser aquela que acarreta um aporte de maior familiaridade 
no reconhecimento da forma, que tipifica o grupo de artrópodes em causa (Correia, 2012).

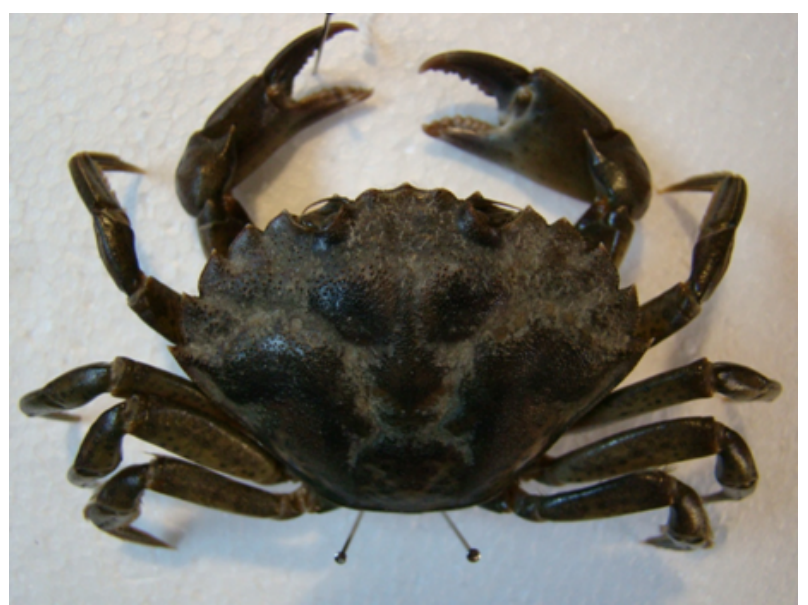

Figura 1. Fotografia de Carcinus maenas em vista dorsal (Ferreira, 2012)

A representação do indivíduo pela técnica do Carbon Dust passou depois por um processo de ensaios gráficos em lápis de grafite que terminaram num desenho preliminar de contorno, à escala (3,2:1), o qual foi transferido, indiretamente, para a folha onde a arte final foi executada (figura 2). O pó de carvão foi produzido abrasando lápis de carvão natural de videira em lixa de água e recolhido em caixa plástica. O pincel seco (pelos de marta Kolinsky, série 7 da Windsor \& Newton) foi depois sujo com este pó, o qual graças às escamas de cada pelo o permitiu transportar para a área a preencher. Na realidade esta técnica simula o princípio técnico da pintura a pincel seco, substituindose a tinta pelo pó de carvão e este é levemente arrastado pela superfície, e em simultâneo o do esfumato da técnica do lápis de grafite (o que permitirá construir paulatinamente gradientes suaves de contraste crescente). O volume que induz a perceção visual de tridimensional é conseguida pela construção e desconstrução (por raspagem ou scratch, com recurso a lâminas) de gradientes monotonais (Froeshner \& Druckenbrod, 2003), sendo que se codifica o branco da superfície de papel como a luz máxima (a guardar) e a sua ausência é dado pelo negro do carvão na expressão máxima (a adicionar, mascarando 
o branco). O efeito é assim conseguido pela dualidade das características do meio que risca e daquele que é riscado.

Em fim último e para reforçar a enfatização da luz foi utilizado um terceiro meio, que permite manter o trabalho anterior intocável, se recorreu à sobreposição de uma película de acetato próprio para inkjet, no qual se reforçam os brilhos por adição do opaco guache branco de titânio e se reforçam as sombras por adição de guache preta (figura 3).

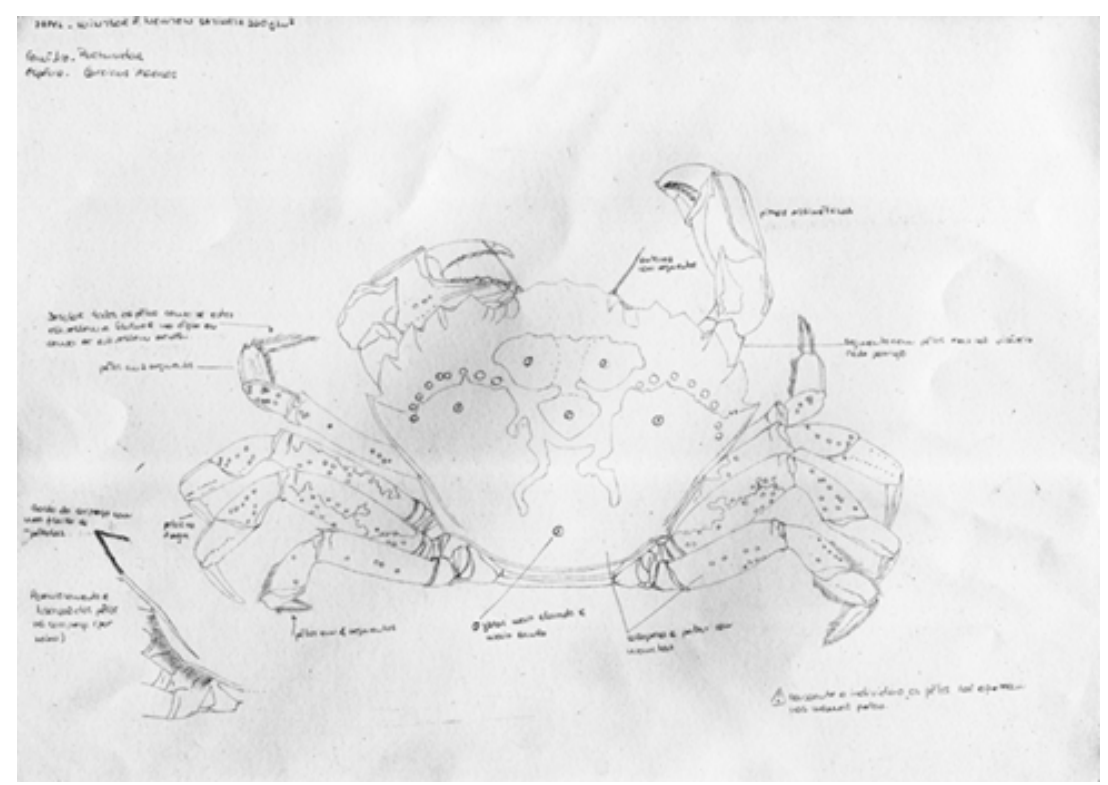

Figura 2. Estudo do espécime e desenho preliminar (Ferreira, 2013) 


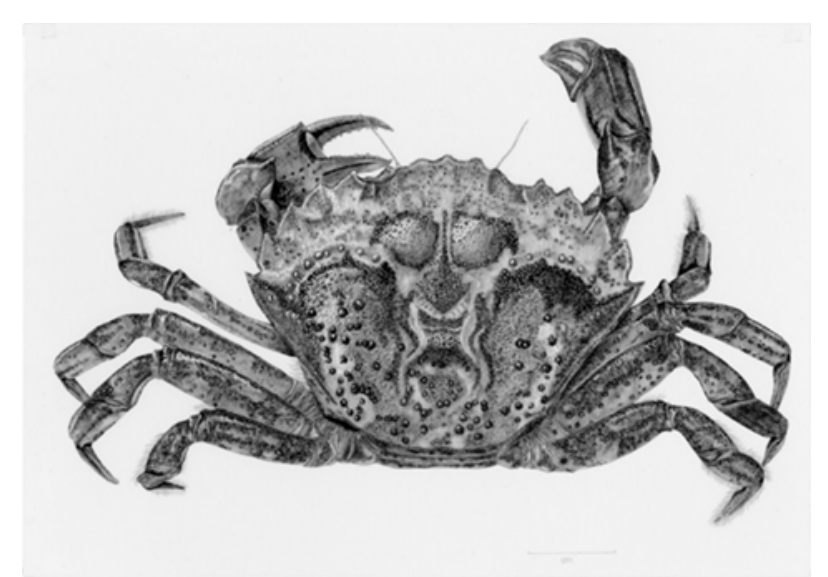

Figura 3. Ilustração final de Carcinus maenas executada em Carbon Dust

(Ferreira, 2013)

Esta técnica flexível permite grandes variações tonais próprias e necessárias a ilustração científica, variando desde uma paleta de cinzas muito claros até ao negro intenso. Relembramos que Max Brödel considerava que a fotografia por si só era insuficiente, observação que o nosso próprio estudo corrobora. O primeiro obstáculo que apresenta a fotografia é que esta apenas fotografa o individuo, o qual pode ser atípico para a espécie, ou não estar na melhor das suas formas (danificado). Por outro lado, o posicionamento da luz aquando da exposição fotográfica pode alterar a percepção da textura (e na leitura desta, sem o exemplar para comparação, uma concavidade pode ser confundida com uma convexidade, por ex.). Assim sendo, existem pressupostos e convenções universalmente adoptados para a ilustração científica que devem ser respeitados, que constituem normas, como seja a orientação da luz (um único foco, com luz incidente migrando do canto superior esquerdo, em diagonal, em direção ao canto inferior direito) que incide no indivíduo. A fotografia apresenta um outro aspeto problemático, a focagem em múltiplos planos, principalmente em objetos de elevado volume: não se consegue recorrendo a uma única fotografia obter, de modo nítido, todos os planos focais (desde a unha das patas ao topo da ornamentação da carapaça, por ex.; atualmente conseguido apenas com focus stacking e sobreposição de várias fotografias do mesmo objeto obtidas com variação da profundidade de campo e 
pós-processamento com software adequados). Esta problemática é facilmente resolvido pela ilustração científica, como os resultados demonstram (figuras 4 e 5).

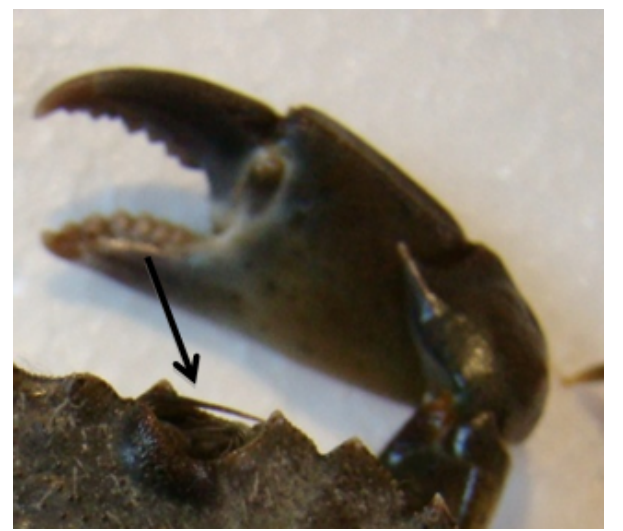

Figura 4. Pormenor fotográfico das antenas e de uma das pinças do espécime que aparece desfocada e em posição post-mortem (Ferreira, 2012)

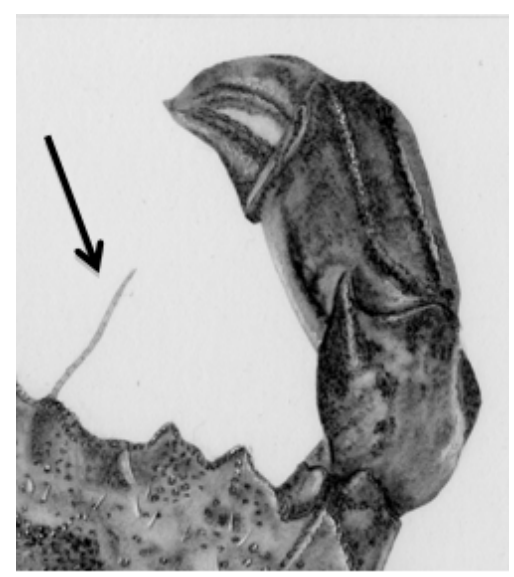

Figura 5. Pormenor ilustrado das antenas recolocadas na sua posição normal e de uma das pinças do espécime (Ferreira, 2013) 
Embora para este trabalho não foram realizadas uma vista ventral e da face do indivíduo, a mesma prancha poderia conter vários pormenores característicos destas faces tais como o aparelho bucal, os olhos ou ainda a forma do abdómen. Se olharmos atentamente a fotografia que segue na figura 6 não se conseguem observar o posicionamento correto das cerdas do animal por este estar fora do seu ambiente natural, a água. No entanto, na ilustração do espécime estes foram desenhados e aparecem nitidamente junto ao corpo e as patas (figura 7). A ilustração das várias especificidades anatómicas, muitas delas reconstruídas e/ou reconfiguradas, e que ainda podem ser mais ou menos enfatizadas através desta metodologia e técnica, justifiquem plenamente a sua utilização preferencial em detrimento da fotografia, uma vez que a ilustração científica tem capacidade de enfoque e elimina ainda todo e qualquer ruído visual que pode ser fator de distração na qualidade da mensagem visual a ser transmitida e assimilada.

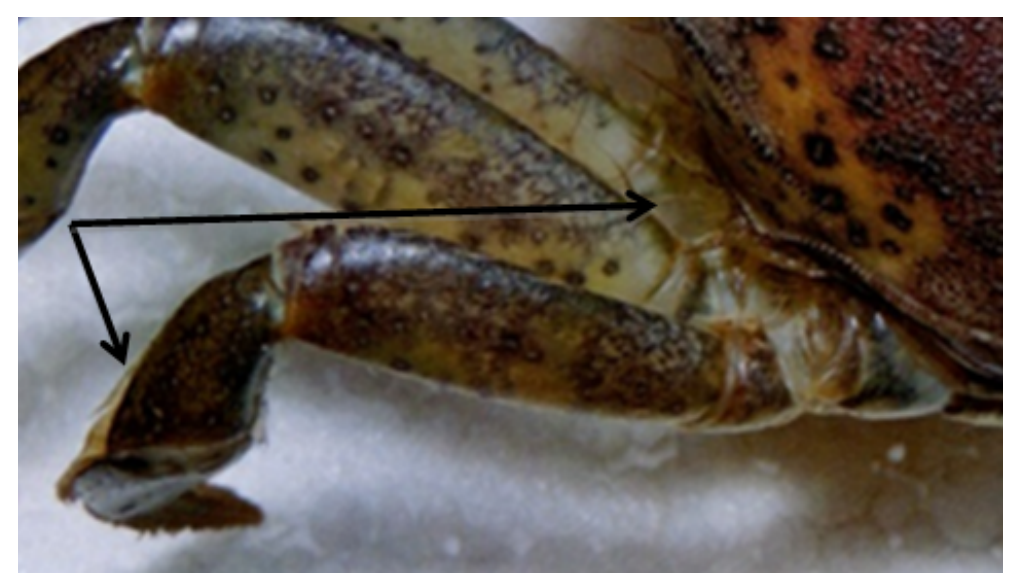

Figura 6. Pormenor fotográfico das cerdas do espécime, afetado pela profundidade de campo, brilhos de reflexão, zonas super- e sub-expostas (Ferreira, 2012) 


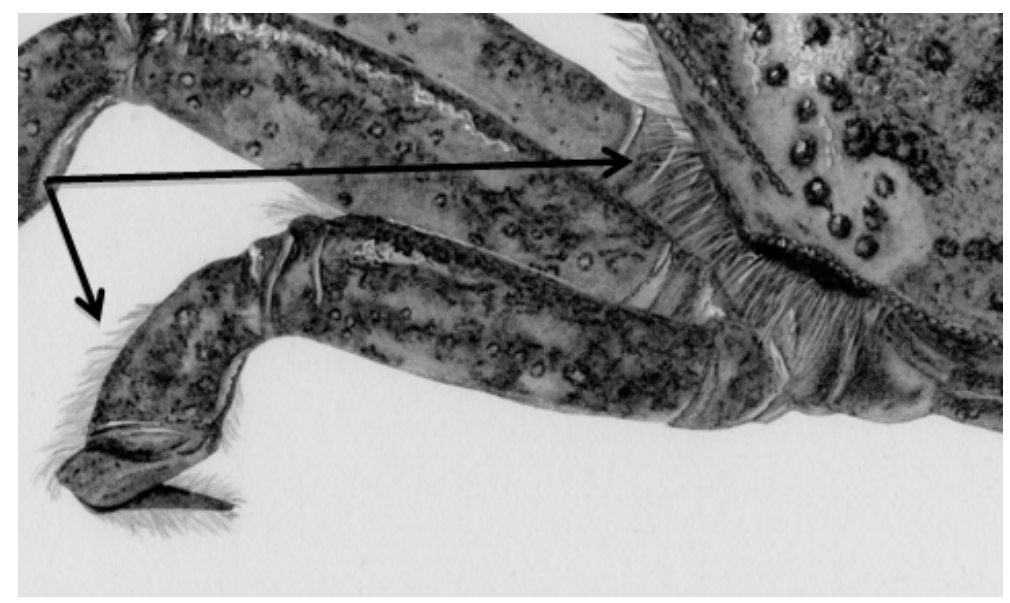

Figura 7. Pormenor ilustrado das cerdas do espécime, com destaque também das articulações, do padrão de superfície e sua textura/ornamentação (Ferreira, 2013)

Mais recentemente o desenvolvimento das técnicas de ilustração digital recorrendo a programas de edição de imagem, tais como Adobe Photoshop, tem permitido igualmente a criação de ilustrações monotonais, importando a metodologia e método de trabalho apreendido nas técnicas clássicas, como a do carvão. Para se conseguirem os mesmo efeitos, a superfície tonalizada homogeneamente de cinzento, pode ser tintada por aplicação direta e variada de tons de cinzento através das ferramentas pincel/aerógrafo/gradiente ou ainda ser escurecida recorrendo à ferramenta "Burn", ou então à ferramenta "Dodge", que clareia as áreas sobre a qual incide (Correia, 2008). Uma não substitui a outra, até porque a técnica clássica pode mimetizar com maior facilidade a textura da superfície externa do espécime, aproveitando a textura do próprio papel traduzida e colocada em evidência pelo depositar do pó de carvão, enquanto nas técnicas digitais se utilizar o APS, toda a textura terá que ser construída ou simulada (muito embora existam programas em que é possível parametrizar as caraterísticas da superfície a pintar - Corel Painter - simulando não só os papéis mas os meios de tintagem e risco clássicos). Poder-se-á ainda dar o caso em que a ilustração iniciada em Carbon Dust, depois de traduzida em bitmaps e importada para uma das aplicações acima referida seja retrabalhada e arte-finalizada em ambiente digital, ou vice-versa, 
conseguindo-se uma muito profícua complementaridade, cheia de potencialidades, assente do desdobrar dos recursos ou ferramentas que pode melhor responder à celeridade com que a informação científica deve ser debitada, sem perder qualidade. Assim, a abordagem mais classicista não se extingue e, muito pelo contrário, integra-se, em plena e bem conseguida adaptação, aos novos tempos e necessidades.

Max Brödel, graças à sua iluminada contribuição, continua como a referência do momento em que Arte entrou e integrou a Medicina, como o veículo essencial para uma melhor comunicação científica dos factos médicos. Ele é uma das provas em como as percepções evoluem e mudam com base nos resultados traduzidos por determinada técnica, cuja pertinência conduz a que a sua validade perdure, evoluindo também, catapultando a comunicação científica, médica, biológica ou outra, para níveis de excelência que melhor respondem às necessidades dos pares científicos, do universo de escolares e da sociedade em geral.

\section{Bibliografia}

Barres, J.M. \& Muñoz, P. (2000). Atlas de Zoologia. Espanha: FGP Editores.

Combier, J. \& Jouves, G. (2014). Nouvelles recherches sur l'identité culturelle et stylistique de la grotte Chauvet et sur sa datation par la méthode du ${ }^{14}$ C. L'anthropologie, 118: 115-151.

Correia, F. (2008a). Reciclar - do velho fazer novo. Advanced Photoshop (A)PS Arte Digital, 11: 31-34.

Correia, F. (2009a). Ilustração Científica - desenhar o saber e o saber do desenho. Biologia \& Sociedade, 8: 39-41.

Correia, F. (2010). Ilustração Científica em Portugal - a génese e o ensino. Anais do III Encontro Nacional de Ilustradores Científicos: Ed. em Pdf/CD (pp. 14-35). Brasília, Brasil: Associação dos Ilustradores Científicos do Centro-Oeste Brasileiro.

Correia, F. (2011a). A Ilustração Científica - "santuário" onde a Arte e a Ciência comungam. Visualidades, 9/2: 221-239.

Correia, F. (2011b). Ilustração Científica - imagem sobre (-o-) natural. Parques e Vida Selvagem, 35: 45-47. 
Correia, F. (2011c). Retratos Naturais - Vamos desenhar... um pardal. Parques e Vida Selvagem, 35: 48-49.

Correia, F. (2012). Retratos Naturais - Vamos desenhar... um grilo. Parques e Vida Selvagem, 38: 50-51.

Correia, F.J. \& Ismar, C. (2015). Paleoarte. Brasil: (in publication).

Czegledy, N. (2010). Women at the threshold of art and medicine. Comunicado do Congresso Internacional Mujer, Arte y Tecnología en la Nueva EsferaPública. Retrieved from www.upv.es. Valéncia, Espanha: Universidade Politècnica de València.

Froeshner, E.H. \& Druckenbrod, L.M. (2003). The Guild Handbook of Scientific Illustration. In E. Hodges, S. Buchanan, J. Cody \& T. Nicholson (Eds.), Carbon Dust (pp. 151-160). New Jersey, NJ: John Wiley \& Sons, Inc.

Saldanha, L. (2003). Fauna Submarina Atlântica - Portugal continental. Açores. Madeira. Mem Martins, Portugal: Publicações Europa-América.

Shultheiss, D. \& Jonas, U. (1999). Max Brödel (1870-1941) and Howard Kelly (1858-1943) - Urogynecology and the birth of modern medical illustration. European Journal of Obstetric \& Gynecology and Reproductive Biology, 86: 113-115.

Shultheiss, D.; Engel, R.M.; Crosby, R.W.; Lees, G.P.; Truss, M.C. \& Jonas, U. (2000). Max Brödel (1870-1941) and medical illustration in urology. The Journal of Urology, 166: 1137-1142.

Stanyer, P.W. (2003). The Complete Book of Drawing Techniques - a professional guide for the artist. In P.W. Stanyer, Charcoal-Charcoal, Conte e Crayons and Compressed Charcoal (pp. 80-140). London, L: Arcturus Publishing Ltd. 